\title{
STUDI KAPASITAS INFILTRASI METODE HORTON \\ UNTUK PEMAKAIAN BIOPORI DI KAMPUS UNIVERSITAS BINA NUSANTARA BERDASARKAN DEBIT LIMPASAN PERMUKAAN
}

\author{
Juliastuti; Andryan Suhendra \\ Civil Engineering Department, Faculty of Engineering, Binus University \\ Jl. K.H. Syahdan No. 9, Palmerah, Jakarta Barat 11480 \\ juliastuti@binus.edu
}

\begin{abstract}
Changes in land use due to the rapid growth of building construction leads to an increase in direct runoff, as well as declining water that seeped into the ground. Consequently, water distribution happens to be unequal of between the rainy and dry seasons. This phenomenon also occurs in the area of Kijang Campus Bina Nusantara University which always comes up with puddles even though the rain falls with only a short duration. In this research the rainfall on the Kijang Campus - Bina Nusantara University is assessed based on the rainfall data record to obtain the rainfall intensity of various periods. Field survey is conducted to determine the existing infiltration capacity (with / without bio pore holes) and on-site. It is concluded based on the research results using Horton method that the soil on the Kijang Campus - Bina Nusantara University is earth embankment that has the infiltration capacity ranging between $0.0867-0.2165 \mathrm{~m} 3 / \mathrm{hr}$. This illustrates that the soil infiltration capacity is relatively small and thus requires the installation of bio pore holes with distance by 0.5 meters.
\end{abstract}

Keywords: infiltration, Horton, bio pore holes,

\begin{abstract}
ABSTRAK
Perubahan tata guna lahan akibat pembangunan yang begitu cepat menyebabkan meningkatnya aliran permukaan langsung, sekaligus menurunnya air yang meresap ke dalam tanah. Akibat selanjutnya adalah distribusi air semakin timpang antara musim penghujan dan kemarau. Fenomena ini terjadi juga pada kawasan kampus Kijang Universitas Bina Nusantara yang selalu mengalami genangan meski hujan turun dengan durasi singkat. Dalam penelitian ini curah hujan di kampus Kijang Universitas Bina Nusantara dikaji berdasarkan catatan data curah hujan untuk mendapatkan intensitas hujan berbagai periode ulang. Survey lapangan dilakukan untuk mengetahui kapasitas infiltrasi (dengan/tanpa biopori) eksisting dan di lokasi pengkajian. Berdasarkan hasil penelitian menggunakan metode Horton, dapat diambil kesimpulan bahwa tanah di kampus Kijang Universitas Bina Nusantara adalah tanah timbunan yang memiliki kapasitas infiltrasi berkisar antara 0.0867 - 0.2165 m3/jam. Hal ini menggambarkan bahwa kemampuan infiltrasi tanah relatif kecil sehingga membutuhkan pemasangan biopori dengan jarak dekat yaitu 0.5 meter.
\end{abstract}

Kata kunci: Infiltrasi, Horton, Biopori, Limpasan Permukaan 


\section{PENDAHULUAN}

Kampus kijang Universitas Bina Nusantara terletak di Jl. Kemanggisan Ilir III No. 45, Kecamatan Palmerah, Jakarta Barat. Pada saat ini area perkarangan kampus ini kerap menghadapi permasalahan banjir. Sebagian besar saluran drainase di area tersebut pada saat hujan sebenarnya masih mampu menampung air hujan yang turun. Sayangnya, semakin lama tinggi genangan semakin tinggi. Meski area depan kampus dan parkiran motor sudah dibuatkan tanggul, ketika hujan datang air tetap masuk ke dalam ruangan.

Keadaan ini semakin dipersulit dengan terjadinya perkembangan tata guna lahan yang semakin pesat terutama berkembangnya usaha penyediaan kos-kosan mahasiswa dan usaha di bidang makanan yang secara langsung berdampak pada meningkatnya debit air kotor/genangan. Hal ini diperparah dengan elevasi muka tanah di kampus Kijang semakin lama semakin rendah karena semakin tingginya elevasi permukaan tanah di sekitar Kijang akibat pembangunan/renovasi bangunanbangunan baru. Hal ini menyebabkan limpasan permukaan sebagian besar mengalir ke kampus Kijang. Oleh karena itu diperlukan adanya suatu penelitian yang bertujuan untuk mengurangi tinggi genangan melalui resapan pada daerah-daerah hijau sehingga genangan dapat cepat berkurang melalui serapan alami yang secara langsung dapat mengisi air tanah (recharge area). Penelitian dilakukan pada kampus Kijang, Universitas Bina Nusantara. Sedangkan untuk titik pengambilan sampel dilakukan pada tujuh titik yang tersebar di daerah tersebut (Gambar 1).

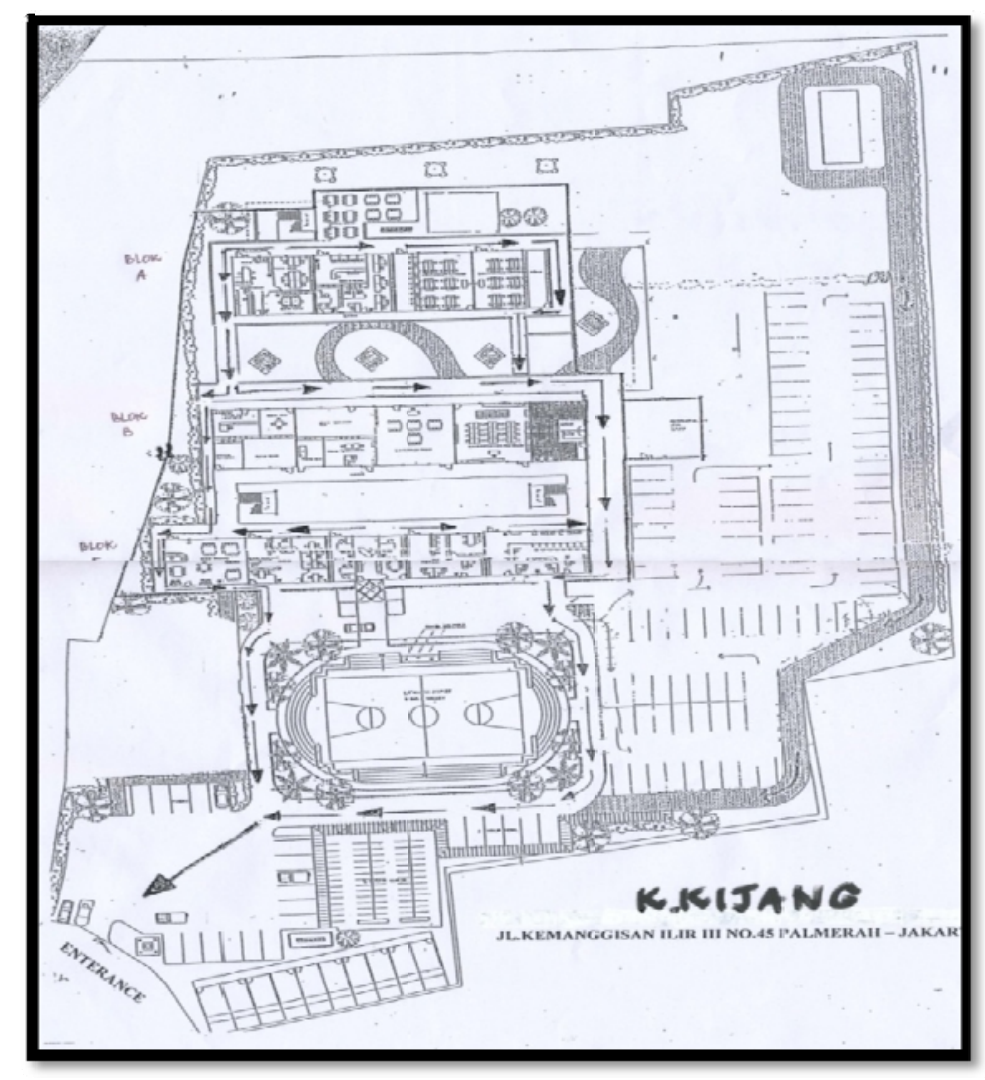

Gambar 1. Lokasi Penelitian.

Dengan demikian tujuan dari penelitian ini adalah: (1) mengevaluasi besarnya debit air hujan yang jatuh pada kawasan kampus Kijang Universitas Bina Nusantara sebagai lokasi penelitian; (2) 
mengetahui besarnya laju infiltrasi pada lokasi penelitian; (3) merancang banyaknya biopori yang dapat dipasang pada lokasi penelitian. Adapun manfaat dari penelitian ini adalah: (1) mendapatkan upaya/gagasan pengendalian genangan melalui pemanfaatan biopori; (2) dapat dipakai sebagai pedoman dalam merancang jumlah dan letak biopori sebagai salah satu alternatif untuk mengurangi genangan.

\section{METODE}

Untuk mempermudah penelitian ini diperlukan pendekatan atau metodologi penelitian yang di mulai dari pengumpulan data-data. Pengumpulan data dibagi menjadi dua bagian yaitu pengumpulan data primer dan pengumpulan data sekunder. Data primer didapat dari pengukuran di lapangan yang dilakukan di Kampus Kijang - Universitas Bina Nusantara, Jakarta Barat, yang terdiri dari: (1) data laju infiltrasi tanah yang diukur menggunakan ring infiltrometer karena metode pengukuran ini sangat mudah dalam penerapan di lapangan dan lebih murah dibanding dengan simulator hujan dan sesuai dengan keadaan tanah di lapangan. Ring infiltometer adalah suatu pipa besi yang bergaris tengah $25-30 \mathrm{~cm}$ dengan tinggi $60 \mathrm{~cm}$. Pada bagian atas pipa terdapat plat yang berfungsi memudahkan dan melindungi ring pada saat ditekan. Pada penelitian ini double ring infiltrometer tidak digunakan karena kondisi tanah merupakan tanah urugan batu. Selain itu dibutuhkan gaya atau tenaga yang besar untuk melakukan penetrasi untuk ring yang berdiameter besar; (2) data permeabilitas tanah yang diuji di laboratorium tanah; (3) data laju infiltrasi dengan pada lubang resapan biopori. Data primer yang didapat dari hasil pengukuran di lapangan dianalisis dengan langkah-langkah seperti pada Gambar 2:

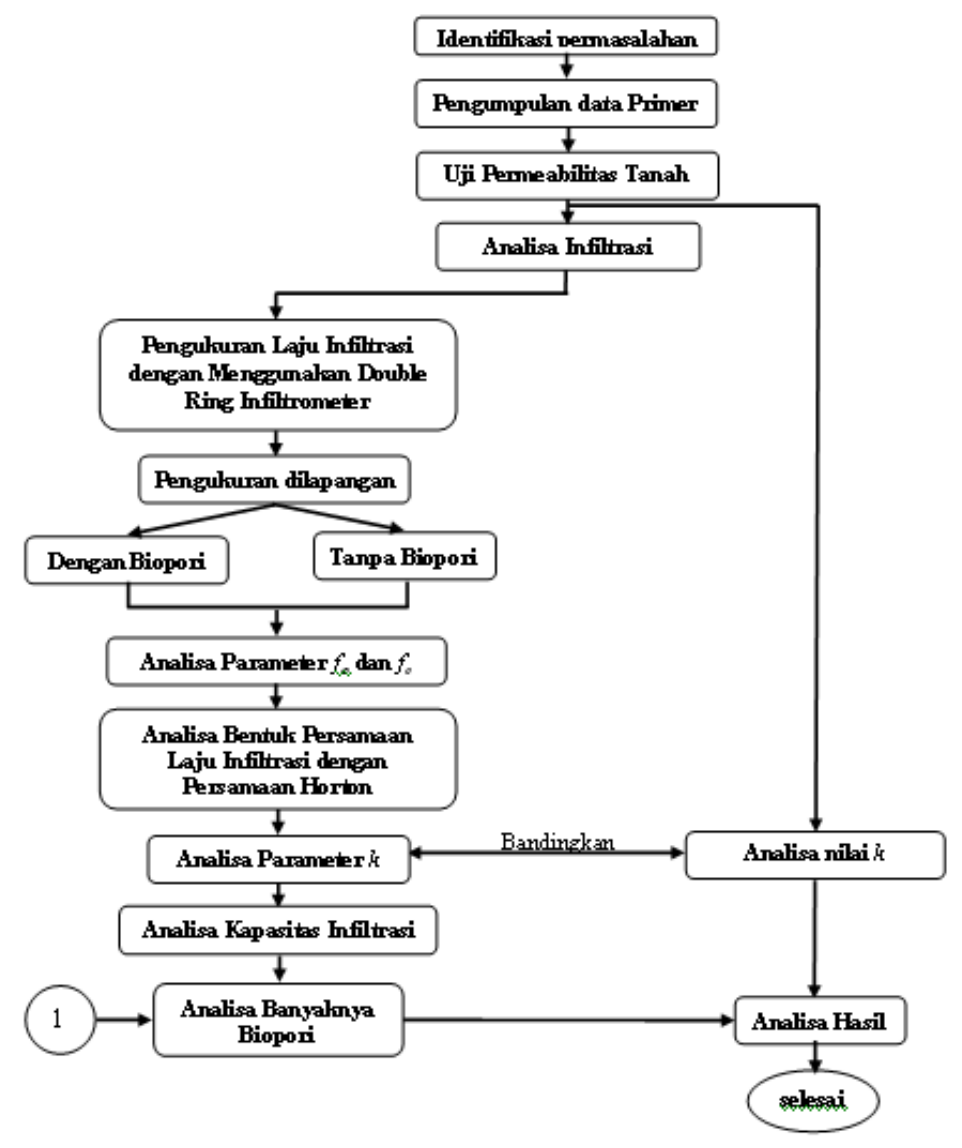

Gambar 2. Diagram tahapan analisis biopori. 
Data sekunder didapat dari badan Meteorologi, Klimatologi dan Geofisika (BMKG), Jakarta Pusat dari tahun 1990 sampai 2002. Data tersebut adalah besarnya curah hujan dikawasan Cengkareng, Jakarta Barat. Data curah hujan tersebut hanya dapat diambil dari tahun 1990 sampai 2002 disebabkan karena data soft copy yang terbaru hanya sampai tahun 2002. Data curah hujan yang didapat nantinya akan digunakan untuk menghitung distribusi frekuensi curah hujan. Selain data tersebut luas area pengukuran dan detail letak titik pengambilan sample juga digunakan untuk penelitian ini dan data tersebut didapat dari Building Management Universitas Bina Nusantara.

Pengolahan data curah hujan rencana dilakukan dengan metodologi berikut: (1) pemeriksaan data hujan maksimum harian dari pos hujan yang tersedia di sekitar lokasi studi; (2) analisis frekuensi untuk menentukan distribusi statistik yang sesuai dengan kondisi data pos hujan yang ada; (3) distribusi statistik yang dicoba adalah distribusi Normal, Log-Normal, Gumbel dan Log-Pearson Tipe III. Sedangkan kecocokan data terhadap distribusi diuji berdasarkan kriteria Chi-Kuadrat serta Kolmogorov-Smirnov; (4) analisis intensitas curah hujan rencana.

Perhitungan laju infiltrasi menggunakan metode Horton (1933, 1939). Horton mengamati bahwa infiltrasi berawal dari suatu nilai baku $f_{o}$ dan secara eksponen menurun sampai pada kondisi konstan $f_{c}$. Salah satu persamaan infiltrasi paling awal yang dikembangkan oleh Horton adalah:

$$
f(t)=f_{c}+\left(f_{o}-f_{c}\right) e^{-k t}
$$

dimana $k$ adalah pengurangan konstan terhadap dimensi $\left[\mathrm{T}^{-1}\right] . f_{o}$ adalah kapasitas infiltrasi awal. Sedangkan $f_{c}$ adalah kapasitas infiltrasi konstan yang tergantung pada tipe tanah. Parameter $f_{o} \operatorname{dan} f_{c}$ didapat dari pengukuran di lapangan menggunakan alat double ring infiltrometer. Parameter $f_{o}$ dan $f_{c}$ adalah fungsi jenis tanah dan tutupan. Untuk tanah berpasir atau berkerikil nilai tersebut tinggi, sedang tanah berlempung yang gundul nilainya kecil, dan apabila permukaan tanah ada rumput nilainya bertambah.

Eagleson (1970) dan Raudkivi (1979) telah perlihatkan bahwa persamaan Horton diperoleh dari persamaan Richard dengan mengasumsikan bahwa $K$ dan $D$ adalah mutlak tetap dari kadar kelembaban suatu tanah. Kondisi di bawah merupakan turunannya yaitu:

$$
\frac{\partial \theta}{\partial t}=D \frac{\partial 2 \theta}{\partial Z 2}
$$

yang merupakan bentuk standar dari satu persamaan campuran dan untuk mengetahui lengas kadar kelembapan $\theta$ sebagai satu fungsi waktu dan kedalaman. Hasil persamaan Horton didapat dari penyelesaian untuk laju dari kelembaban campuran $D(\partial z / \partial \theta)$ pada permukaan tanah, sehingga jumlah total air yang terinfiltrasi pada suatu periode tergantung pada laju infiltrasi dan fungsi waktu. Apabila laju infiltrasi pada suatu saat adalah $f_{(t)}$, laju infiltrasi kumulatif atau jumlah air yang terinfiltrasi adalah $F_{(\mathrm{t})}$. laju infiltrasi dan jumlah air yang terinfiltrasi adalah:

dan

$$
f_{(t)}=\frac{d F_{(t)}}{d t}
$$

$$
F_{(t)}=\int_{0}^{t} f_{(t)}
$$

Persamaan di atas menunjukkan bahwa jumlah air yang terinfiltarasi $F_{(t)}$ merupakan integral dari laju infiltrasi, sehingga persamaan tersebut menjadi:

$$
\begin{gathered}
F_{(t)}=\int_{0}^{t} f_{c}+\left(f_{0}-f_{c}\right) e^{-k t} d t \\
F_{(t)}=f_{c} t+\frac{1}{k}\left(f_{0}-f_{c}\right)\left(1-e^{-k t}\right) d t
\end{gathered}
$$




\section{HASIL DAN PEMBAHASAN}

\section{Penentuan Metode Perhitungan Intensitas Hujan}

Pemilihan ini dimaksudkan untuk menentukan persamaan intensitas hujan yang paling mendekati untuk daerah perencanaan. Metode yang digunakan adalah perhitungan dengan cara kuadrat terkecil sebagai berikut: (1) menentukan minimal 7 jenis lamanya curah hujan $t$ (menit), (misalnya 5, $10,20,40,60,80,120)$; (2) menggunakan harga-harga $t$ tersebut untuk menentukan besarnya intensitas hujan untuk periode ulang tahun tertentu (disesuaikan dengan perhitungan debit puncak rencana); (3) menggunakan harga $t$ yang sama untuk menentukan tetapan-tetapan dengan cara kuadrat terkecil. Perhitungan tetapan-tetapan untuk setiap rumus intensitas hujan adalah sebagai berikut:

Tabolt:

$$
\begin{aligned}
& I=\frac{a}{t+b} \\
& a=\frac{\left(I^{2} I t\right)-\left(\left(I^{2} t\right) I\right)}{\left(7 I^{2}\right)-(I . I)} \\
& b=\frac{(I . I t)-\left(\left(I^{2} t\right) 7\right)}{\left(7 I^{2}\right)-(I . I)}
\end{aligned}
$$

Sherman:

$$
\begin{aligned}
I & =\frac{a}{\sqrt{t+b}} \\
a & =\frac{\left(\left[I^{2}\right][I \sqrt{t}]\right)-\left[I^{2} \sqrt{t}\right][I]}{n\left(I^{2}\right)-(I . I)} \\
b & =\frac{([I][I \sqrt{t}])-n\left[I^{2} \sqrt{t}\right]}{n\left(I^{2}\right)-(I . I)}
\end{aligned}
$$

Ishiguro

$$
I=\frac{a}{t^{n}}
$$

$\log a=\frac{[\log I]\left[(\log t)^{2}\right]-[\log t \cdot \log I][\log t]}{n\left[(\log t)^{2}\right]-[\log t][\log t]}$

$n=\frac{[\log I]\left[(\log t)^{2}\right]-n[\log t \cdot \log I]}{n\left[(\log t)^{2}\right]-[\log t][\log t]}$

Nilai data yang dihasilkan oleh (persamaan Talbot, Sherman, dan Ishiguro) dibandingkan dengan nilai intensitas (persamaan Van Breen dan Hasper Der Weduwen). Hasil perhitungan uji kecocokan pada perhitungan menunjukkan bahwa dengan menggunakan metode Hasper Der Weduwen menggunakan persamaan pola Talbot mempunyai selisih Terkecil (Tabel 1).

Tabel 1

Intensitas Hujan Menurut Hasper Der Weduwen dengan Pola Talbot

\begin{tabular}{cccc}
\hline \multirow{2}{*}{$\begin{array}{c}\text { Durasi } \\
\text { (Menit) }\end{array}$} & \multicolumn{3}{c}{ Intensitas (mm/mnt) } \\
\cline { 2 - 4 } & PUH 2 & PUH 5 & PUH 10 \\
\hline 5 & 370,2659 & 397,2277 & 412,1204 \\
10 & 125,4571 & 141,6975 & 151,5946 \\
20 & 54,0218 & 61,9695 & 66,9493 \\
30 & 34,4220 & 39,6564 & 42,9612 \\
60 & 16,4821 & 19,0637 & 20,7051 \\
80 & 12,2321 & 14,1613 & 15,3900 \\
120 & 8,0702 & 9,3516 & 10,1690 \\
\hline
\end{tabular}




\section{Analisis Hasil Pengukuran Laju Infiltrasi}

Seperti yang telah dipaparkan sebelumnya bahwa data yang diperoleh melalui hasil pengukuran laju infiltrasi menggunakan ring infiltrometer yang dilakukan pada 14 titik baik dengan biopori ataupun tanpa biopori yang tersebar (Tabel 2). Titik-titik tersebut dapat mewakili laju infiltrasi pada kampus Kijang, Universitas Bina Nusantara yang dianalisis menggunakan metode Horton. Dalam Perhitungan laju infiltrasi menggunakan metode Horton, rumusan yang dipakai yaitu:

$$
f(t)=f_{c}+\left(f_{o}-f_{c}\right) e^{-k t}
$$

Tahapan-tahapan perhitungan metode Horton dapat dijelaskan sebagai berikut:

$f(t)-f_{c}=\left(f_{o}-f_{c}\right) e^{-k t}$

$\log \left(f(t)-f_{c}\right)=\log \left(f_{o}-f_{c}\right)-\mathrm{kt} \log e$

$m=\frac{-1}{k \log e}$

Tabel 2

Perbandingan Laju Infiltrasi

\begin{tabular}{|c|c|c|}
\hline Titik & $\begin{array}{c}\text { Tanpa Biopori } \\
\text { Laju Infiltrasi } \\
\text { rata - rata }\end{array}$ & $\begin{array}{c}\text { Dengan Biopori } \\
\text { Laju infiltrasi } \\
\text { rata - rata }\end{array}$ \\
\hline $\mathrm{A}$ & 2 & 20 \\
\hline B & 7 & 8 \\
\hline $\mathrm{C}$ & 4 & 12 \\
\hline D & 2 & 22 \\
\hline E & 9 & 16 \\
\hline $\mathrm{F}$ & 4 & 16 \\
\hline $\mathrm{G}$ & 14 & 30 \\
\hline
\end{tabular}

\section{Analisis Debit Limpasan Terhadap Kapasitas Infiltrasi}

Analisi ini dilakukan untuk mengetahui apakah kapasitas infiltrasi tanah tanpa menggunakan biopori pada kawasan kampus Kijang, Universitas Bina Nusantara mampu menampung debit limpasan air hujan. Jika debit curah hujan lebih besar dari pada debit infiltrasi, dibutuhkan lubang resapan biopori untuk menanggulangi kelebihan debit tersebut. Menghitung debit limpasan menggunakan persamaan berikut ini:

$$
\mathrm{Q}=0,278 \text { CIA }
$$

di mana $C$ adalah nilai koefisien limpasan, $I$ adalah intensitas curah hujan dan $A$ adalah luas area. Berdasarkan rumus tersebut, didapat hasil debit limpasan seperti pada Tabel 3.

Tabel 3

\begin{tabular}{|c|c|c|c|c|c|c|}
\hline \multirow{5}{*}{ Lokasi } & \multicolumn{6}{|c|}{$\mathbf{Q}_{\text {limpasan }}\left(\mathrm{m}^{3} / \mathbf{j a m}\right)$} \\
\hline & \multicolumn{6}{|c|}{ Periode Ulang Hujan (PUH) (tahun) } \\
\hline & 2 & & 5 & & 10 & \\
\hline & \multicolumn{6}{|c|}{ Durasi (t) (menit) } \\
\hline & 60 & 120 & 60 & 120 & 60 & 120 \\
\hline A & 53,9421 & 26,4118 & 62,3911 & 30,6056 & 67,7631 & 33,2808 \\
\hline B & 53,9421 & 26,4118 & 62,3911 & 30,6056 & 67,7631 & 33,2808 \\
\hline $\mathrm{C}$ & 63,0365 & 30,8647 & 72,9099 & 35,7655 & 79,1876 & 38,8918 \\
\hline $\mathrm{D}$ & 71,9484 & 35,2283 & 83,2177 & 40,8219 & 90,3829 & 44,3902 \\
\hline $\mathrm{E}$ & 79,6222 & 38,9856 & 92,0934 & 45,1758 & 100,0228 & 49,1247 \\
\hline $\mathrm{F}$ & 49,0430 & 24,0131 & 56,7246 & 27,8259 & 61,6087 & 30,2582 \\
\hline $\mathrm{G}$ & 88,2367 & 43,2036 & 102,0572 & 50,0635 & 110,8445 & 54,4396 \\
\hline
\end{tabular}

Perhitungan Debit Limpasan dengan Periode Ulang 2, 5 dan 10 Tahun dengan Durasi 1 dan 2 Jam 


\section{Analisis Jumlah Lubang Resapan Biopori}

Hasil dari data debit limpasan bersama dengan kapasitas infiltrasi pada lubang biopori digunakan untuk menghitung jumlah lubang resapan biopori (LRB) seperti pada persamaan berikut ini:

$$
\text { Jumlah LRB }=\mathrm{Q}_{\text {limpasan }} / \text { laju peresapan air per lubang }
$$

Jumlah lubang biopori yang dibutuhkan untuk mencegah adanya genangan dihitung menggunakan $\mathrm{Q}_{\text {limpasan }}$ periode ulang hujan 10 tahunan dan durasi 2 jam (Tabel 4).

Tabel 4

Perhitungan Jumlah LRB dan Jarak LRB

\begin{tabular}{|c|c|c|c|c|c|}
\hline \multirow[t]{2}{*}{ Kawasan } & $\begin{array}{c}Q_{\text {limpasan }} \\
\left(\mathrm{m}^{3} / \mathrm{jam}\right)\end{array}$ & $\begin{array}{c}\text { Jumlah air yang } \\
\text { terinfiltrasi } \\
\left(\mathrm{m}^{3} / \mathrm{jam}\right)\end{array}$ & \multirow[t]{2}{*}{$\begin{array}{c}\text { Jumlah } \\
\text { LRB }\end{array}$} & \multirow[t]{2}{*}{$\begin{array}{c}\text { Luas } \\
\text { kawasan } \\
\left(\mathbf{m}^{2}\right)\end{array}$} & \multirow[t]{2}{*}{$\begin{array}{c}\text { Jarak antar } \\
\text { LRB } \\
\text { (m) }\end{array}$} \\
\hline & 120 & 120 & & & \\
\hline $\mathrm{A}$ & 33,2808 & 0,1459 & 228 & 218,01 & 0,4779 \\
\hline B & 33,2808 & 0,0580 & 574 & 218,01 & 0,1900 \\
\hline $\mathrm{C}$ & 38,8918 & 0,0867 & 449 & 254,7653 & 0,2840 \\
\hline $\mathrm{D}$ & 44,3902 & 0,1604 & 277 & 290,7833 & 0,5254 \\
\hline $\mathrm{E}$ & 49,1247 & 0,1171 & 420 & 321,7973 & 0,3835 \\
\hline $\mathrm{F}$ & 30,2582 & 0,1163 & 260 & 198,21 & 0,3809 \\
\hline G & 54,4396 & 0,2165 & 251 & 356,6133 & 0,7091 \\
\hline
\end{tabular}

Untuk lebih jelas dapat dilihat pada contoh perhitungan jumlah LRB dan jarak LRB dengan $\mathrm{Q}_{\text {limpasan }}$ dengan periode 10 tahun dan durasi 2 jam pada kawasan A berikut ini.

jumlah $L R B=\frac{33,2808}{0,1459}=228$

jarak $L R B=\frac{\mathrm{A}}{\text { jumlah LRB }}$

jarak $L R B=\frac{218,01}{228}=0,4779 \mathrm{~m}$ dibulatkan menjadi $0.5 \mathrm{~m}$

\section{PENUTUP}

Berdasarkan hasil analisis dan perhitungan, dapat dilihat bahwa karakteristik tanah di kampus Kijang, Universitas Bina Nusantara, Jakarta, adalah tanah yang memiliki kapasitas infiltrasi kecil yaitu berkisar antara $0.0867-0.2165 \mathrm{~m}^{3} /$ detik. Hal ini menyebabkan kemampuan daya serap limpasan permukaan menjadi sulit sehingga pemasangan biopori dibutuhkan dengan jarak 0.5 meter.

\section{DAFTAR PUSTAKA}

Harto , S. (1993). Analisis Hidrologi. Jakarta: Gramedia Pustaka Utama.

Loebis, J. (1992). Banjir Rencana untuk Bangunan Air. Jakarta: Yayasan Badan Penerbit Pekerjaan Umum.

Soewarno. (1995). Hidrologi: Aplikasi Metode Statistik untuk Analisis Data, (jilid I dan II). Bandung: Nova.

Sosrodarsono, S. (1993). Hidrologi untuk Pengairan. Jakarta: Pradnya Paramita.

Sukarto, H. (1999). Drainase Perkotaan. Jakarta: Medisa \& Departemen Pekerjaan Umum. 